DOI: 10.4274/ejgg.galenos.2020.378

Eur J Geriatr Gerontol 2021;3(1):4-11

\title{
Nutritional Profile and Serum Uric Acid are Associated with Metabolic Syndrome in Community-dwelling Older Adults: A Cross-sectional Study
}

\author{
(D) Ivna Vidal Freire1,2, (D) Denise Pereira dos Santos1,3, (D) Ícaro JS Ribeiro1,2, (D) Caroline Silva dos Santos1, \\ (D) Raildo da Silva Coqueiro1,4, (D) Cezar Augusto Casotti2,4, (D) Rafael Pereira1,2,3 \\ 1State University of Southwest Bahia Faculty of Medicine, Department of Biological Sciences, Integrative Physiology Research Center, Bahia, Brazil \\ 2State University of Southwest Bahia, Postgraduate Program in Nursing and Health, Bahia, Brazil \\ 3 State University of Southwest Bahia Faculty of Medicine, Bahia, Brazil \\ ${ }^{4}$ State University of Southwest Bahia Faculty of Medicine, Department of Health, Bahia, Brazil
}

\begin{abstract}
Objective: This study aimed to evaluate the prevalence of metabolic syndrome in community-dwelling older adults and compare the nutritional profile in macronutrient and micronutrient intakes and serum uric acid in community-dwelling older adults with and without metabolic syndrome.
\end{abstract}

Materials and Methods: Overall, 155 community-dwelling older adults were enrolled and were stratified into two groups: with and without metabolic syndrome. The estimated daily macronutrient and micronutrient intakes and the single umbilical artery (SUA) were obtained and compared between the groups.

Results: The prevalence rate of metabolic syndrome was 38.7\%, and older adults with metabolic syndrome exhibited greater carbohydrate and lower protein and lipid consumptions. It was observed that the older adults without metabolic syndrome showed higher daily mono- and poly-unsaturated fatty acids, copper and vitamins A and B6 intakes, whereas those with metabolic syndrome exhibited higher daily manganese and vitamin C intakes. Higher SUA was found in older adults with metabolic syndrome, characterising a pro-oxidant state.

Conclusion: The nutritional profile adopted by older adults with metabolic syndrome may induce the development of a worrying pro-oxidant state. High carbohydrate consumption could blind the protective effect of a high antioxidant micronutrient intake.

Keywords: Nutrients, micronutrients, oxidative stress, ageing

\section{Introduction}

Metabolic syndrome (MetS) is a worrying health problem, especially for old adults, owing to a higher risk to developing cardiovascular complications, stroke and atherosclerosis (1). Genetic and lifestyle factors, such as the nutritional profile, are the major factors predisposing to this condition (2).

The prevalence is high among the old adults, reaching 50\% to $63 \%(3,4)$, which is explained by the aging-associated metabolic changes, characterized by the free radicals accumulation and subsequent deoxyribonucleic acid, proteins and lipids damage, compromising the homeostasis and favoring the pathological states, such as the degenerative diseases, cancer, cardiovascular diseases, diseases related to the immune system decline, cerebral dysfunction and cataract (5). Considering that this worrying pro-oxidant state is involved in the genesis of several aging-associated metabolic disorders, preventive actions, such as the adequacy of the macro and micronutrient intake, especially micronutrients with antioxidant potential, is an important intervention to treat and prevent MetS (2).

Address for Correspondence: Rafael Pereira, State University of Southwest Bahia Faculty of Medicine, Department of Biological Sciences, Integrative Physiology Research Center, Bahia, Brazil

Phone: (+55 73) 3528-9616 E-mail: rpfisiologia@gmail.com 0RCID: orcid.org/0000-0003-1800-1450

Received: 07.08.2020 Accepted: 06.10.2020

Cite this article as: Freire IV, dos Santos DP, Ribeiro IJS, dos Santos CS, Coqueiro RDS, Casotti CA, Pereira R. Nutritional Profile and Serum Uric Acid are Associated with Metabolic Syndrome in Community-dwelling Older Adults: A Cross-sectional Study. Eur J Geriatr Gerontol 2021;3(1):4-11

${ }^{\circ}$ Copyright 2021 by the Academic Geriatrics Society / European Journal of Geriatrics and Gerontology published by Galenos Publishing House. 
In this context, participants from 18 to 84 years old, showed that the intake of vitamin $\mathrm{C}$, a relevant antioxidant micronutrient, was lower in subjects with MetS, which increases the risk to develop diabetes and cardiovascular diseases (2). The investigations regarding the micronutrients intake demonstrate relevant insights, but an in-depth analysis, including the investigations of macro and micronutrients intake could provide a larger comprehension about the relationship among nutritional profile and the MetS, especially if the investigations include a biomarker of oxidative stress.

Serum uric acid has been suggested as a biomarker associated with MetS, since it is related to oxidative state (6). This biomarker is interesting when studying the interaction among MetS, nutritional profile and oxidative stress, since it is useful and easily accessible in the evaluation of oxidative stress, and may be directly and indirectly associated with the nutritional profile (6-8). Notwithstanding, the highest serum concentration of uric acid is indicated as an independent risk factor for MetS and target organ damage in Korean old adults $(9,10)$ and the reduction in serum levels of uric acid is presented as a potential strategy for prevention and treatment of systemic metabolic abnormalities in old adults $(6,11,12)$.

Thus, this study aimed to verify the prevalence of MetS in community-dwelling old adults and to compare the nutritional profile in macronutrients and some micronutrients intake, and serum uric acid in community-dwelling old adults with and without MetS.

\section{Materials and Methods}

\section{Studied population}

This was a cross-sectional, home-based, descriptive and analytical study that included all community-dwelling older people ( $\geq 60$ years old) from Aiquara, Bahia, Brazil. Two hundred eighty-nine old adults were screened, but only 155 older adults presented the complete data from the interest variables to meet the proposed aim in this study. Bedridden individuals and/or those with severe cognitive impairment $(n=20)$ were excluded. All procedures were conducted in conformity with the Helsinki Declaration and the study was submitted and approved by the local Human Research Ethics Committee (protocol\#:729.303). Written informed consent was obtained from the volunteers.

Data collection was carried out from January to July 2015, and involved three groups of variables: questionnaires, clinical assessment, and collection of biological samples. Data recordings from the questionnaires, socio-demographic characteristics and self-reported health status were used in this study. After recording questionnaires during home visit, participants were scheduled to attend in Aiquara Municipal Hospital, where they underwent a blood pressure measurement, anthropometric assessment and venous blood withdrawal $(10 \mathrm{~mL}$ from the antecubital vein). Blood samples were used to biochemical analysis and, in this study, the blood triglycerides, high-density lipoprotein (HDL) cholesterol, fasting glycemia and serum acid uric were measured. From clinical assessment, systolic and diastolic blood pressure, height and abdominal circumference measures were used in this study.

Systolic and diastolic blood pressures were assessed using oscillometric method with a validated automatic device (model HEM 742 Intellisense, Omron Healthcare, Inc.). With old adults sitting comfortably, two blood pressure measures were taken 5 minutes apart. All blood pressure measures were taken at morning (08:00-11:30 hours).

The smoking habit, self-reported race, income and age were obtained from socio-demographic questionaries. The physical activity level was obtained from the International Physical Activity Questionnaire, and data were dichotomized according to the proposed cut-point of $150 \mathrm{~min} /$ week of moderate and vigorous activity (i.e., $150 \mathrm{~min} / \mathrm{wk}$, sufficiently active and <150 $\mathrm{min} / \mathrm{wk}$, insufficiently active) (13).

\section{Definition of MetS and serum uric acid dosage}

We used the criteria proposed by National Cholesterol Education Program- Adult Treatment Panel III (NCEP-ATP III) to classify the old adults as with or without MetS, which was diagnosed when at least three of the five listed characteristics are present: abdominal circumference (men $>102 \mathrm{~cm}$, women $>88 \mathrm{~cm}$ ); hypertriglyceridemia ( $\geq 150 \mathrm{mg} / \mathrm{dL}$ ), HDL cholesterol (men $<40$ $\mathrm{mg} / \mathrm{dL}$, women $<50 \mathrm{mg} / \mathrm{dL}$ ), hypertension (prior diagnosis or blood pressure $\geq 130 / 85 \mathrm{mmHg}$ ), and fasting glycemia $\geq 110 \mathrm{mg} /$ $\mathrm{dL}$ or previous diagnosis of diabetes mellitus.

Dosage of triglycerides, HDL cholesterol, fasting glycemia, and serum uric acid was performed using standard laboratory methods in a venous blood sample collected after 8 to 12 hours of fasting and results given in $\mathrm{mg} / \mathrm{dL}$.

\section{Estimated daily calorie intake and nutritional profile}

Daily food and beverages were recorded through a 24-hour recall as recommended by Rutishauser (14) and done by da Silva et al. (15). Researchers were trained to apply the 24-hour recall and data extraction was standardized. Estimated daily calorie and protein intake were calculated using the software DietPro ${ }^{\circledR}$ version 5.8.1. The estimated daily caloric intake was expressed in absolute values (Kcal) and normalized by the resting energy expenditure for each volunteer, then, values below 1.0 indicated that the estimated daily caloric intake was not adequate to the Resting Energy Expenditure, indicating a deficit in the caloric intake. The estimated daily protein intake was expressed in absolute values (grams of protein) and normalized (grams of protein/total body mass). 
The estimated daily intake of mono and polyunsaturated fatty acids and micronutrients (copper, manganese, niacin, riboflavin, vitamins $A, B 6, C$ and zinc) were expressed in absolute values (grams or milligrams).

The estimated daily intake of macro and micronutrients were also calculated with DietPro $^{\circledR}$ software version 5.8.1 and adjusted for the estimated total daily intake, as suggested by Willett et al. (16) and done by da Silva et al. (15).

\section{Statistics}

Normality of the data distribution was tested using the ShapiroWilk test. Considering that, for old adults with MetS, all studied variables did not present normal distribution, the results were presented as median and interquartile range (ie: cut to the first and third quartiles). The chi-square test was used to verify the distribution of the sex between the groups with and without MetS. The Mann-Whitney $U$ test was used to compare the nutritional profile, the serum uric acid concentration and the income between groups. The effect size for each comparison was calculated according to the following equation $r=Z / s q r t(N)$, where $\mathrm{N}$ is the total number of repetitions and $\mathrm{Z}$ is the $\mathrm{Z}$-value obtained from the Mann-Whitney $U$ test (17). An effect size was considered as small when $r \leq 0.1$, medium when $r \geq 0.24$, large when $r \geq 0.37$ (18).

Since the serum uric acid could be influenced by antihypertensive drugs (19), especially beta-blockers, alfa-1 blockers, angiotensinconverting enzyme inhibitors, Calcium channel blockers and angiotensin-II receptor blockers, the association between each antihypertensive drug and MetS diagnoses was analyzed using chi-square test.

The level of significance for all tests was set as $p \leq 0.05$. All statistical procedures were performed with SPSS Statistics software for Windows (SPSS 21.0, 2012, Armonk, NY: IBM Corp.).

\section{Results}

The prevalence of MetS in the studied population was 38.7\%, with a similar distribution of men and women in each group (with MetS $=26$ men and 34 women; without MetS $=41$ men and 54 women; $p>0.05$ ). The mean age was $71.0 \pm 8.2$ and $71.6 \pm 8.0$ years old ( $p>0.05$, mean \pm standard deviation) for old adults with and without MetS, respectively. The income, a socio-demographic variable able to influence the acess to nutrients, was similar between groups [without MetS: R\$ 774.00 (700.00-788.00), with MetS: $R \$ 788.00$ (705.00-788.00), p>0.05]. Table 1 presents other socio-demographic and clinical characteristics of the studied population. There were no differences between groups for self-reported race, smoking habit, and physical activity habit ( $p>0.05$ ). Among clinical characteristics, the prevalence of hypertension was high in the studied population (62.5\%), but the distribution of hypertensive old adults was not different between old adults with and without MetS ( $>>0.05)$. However, the prevalence of diabetes mellitus, hypertriglyceridemia, dyslipidemia (low HDL) and obesity (abdominal circumference) was $23.3 \%, 46.9 \%, 34.4 \%, 71.9 \%$ among the studied population, respectively, and were significantly higher among old adults with MetS $(p<0.05$, see Table 1$)$.

The distribution of daily intake of macronutrients was significantly different between the groups with and without MetS $(p \leq 0.05)$. The old adults with MetS showed a nutritional profile composed by a higher percentage of carbohydrates, while those without MetS had a nutritional profile composed by a greater percentage of lipids and protein (Table 2).

The resting energy expenditure did not present a significant difference between the groups without MetS [1636.27 (1466.291809.17) Kcal] and with MetS [1680.36 (1513.83-1918.41) Kcal] $(p=0.192)$. Similarly, the total energy intake was not significantly different between the groups without MetS [1301.24 (953.751691.35) Kcal] and with MetS [1166.73 (843.79-1567.96) Kcal] $(p=0.400)$.

In addition, the values of normalized estimated daily caloric intake indicated that both groups were below the energy requirements [without MetS: 0.76 (0.56-1.01); with MetS: 0.68 (0.55-0.89)], whithout difference between the groups for this variable $(p=0.180)$. The daily intake of potentially antioxidant nutrients (i.e., monounsaturated and polyunsaturated fatty acids and micronutrients) revealed a significantly higher daily intake of mono and polyunsaturated fatty acids, copper and vitamins $A$ and $B 6$ among old adults without MetS, while those with MetS exhibited a higher daily intake of manganese and vitamin C (Table 2).

Serum uric acid was significantly higher in the MetS group compared to the without MetS group [without MetS: 6.69 (6.60-6.80) mg/dL, with MetS: 7.43 (7.35-7.54) mg/dL, $p<0.001$, effect size $(r)=0.76]$ (Figure 1).

There was not observed significant association between antihypertensive drugs use and studied old adults with and without MetS ( $p>0.05$, see Table 3 ). Then the proportion of old adults with and without MetS using each relevant class of antihypertensive drugs was similar, wich is relevant, since the serum uric acid levels could be influenced by antihypertensive drugs.

\section{Discussion}

The present study aimed to verify the prevalence of MetS in community-dwelling old adults and to compare the nutritional profile in macronutrients and some micronutrients intake, and serum uric acid in community-dwelling old adults with and without MetS. The main results of this study showed a high prevalence of MetS in the studied population, and a higher 


\begin{tabular}{|c|c|c|c|c|}
\hline Variables & & Without MetS & With MetS & p \\
\hline \multirow{2}{*}{ Race/color } & White & $10(11.1 \%)$ & $8(13.3 \%)$ & \multirow{2}{*}{0.682} \\
\hline & Nonwhite & $80(88.9 \%)$ & $52(86.7 \%)$ & \\
\hline \multirow{2}{*}{ Smoking habit } & No & 78 (88.6\%) & $52(92.9 \%)$ & \multirow{2}{*}{0.405} \\
\hline & Yes & $10(11.4 \%)$ & $4(7.1 \%)$ & \\
\hline \multirow{2}{*}{ Physical activity habit } & Sufficiently active & $53(57.6 \%)$ & $29(52.7 \%)$ & \multirow{2}{*}{0.564} \\
\hline & Insufficiently active & $39(42.4 \%)$ & $26(47.3 \%)$ & \\
\hline \multirow{2}{*}{ Hypertension } & No & $36(37.9 \%)$ & $22(36.7 \%)$ & \multirow{2}{*}{0.878} \\
\hline & Yes & $59(62.1 \%)$ & $38(63.3 \%)$ & \\
\hline \multirow{2}{*}{ Diabetes } & No & $82(86.3 \%)$ & $37(61.7 \%)$ & \multirow{2}{*}{$<0.001$} \\
\hline & Yes & $13(13.7 \%)$ & $23(38.3 \%)$ & \\
\hline \multirow{2}{*}{ Dyslipidemia* } & No & $58(65.2 \%)$ & $20(34.5 \%)$ & \multirow{2}{*}{$<0.001$} \\
\hline & Yes & $31(34.8 \%)$ & $38(65.5 \%)$ & \\
\hline \multirow{2}{*}{ Hypertriglyceridemia** } & No & $82(87.2 \%)$ & $19(31.7 \%)$ & \multirow{2}{*}{$<0.001$} \\
\hline & Yes & $12(12.8 \%)$ & $41(68.3 \%)$ & \\
\hline \multirow{2}{*}{ Obesity ${ }^{* * *}$} & No & $33(38.4 \%)$ & 8 (13.3\%) & \multirow{2}{*}{0.001} \\
\hline & Yes & $53(61.6 \%)$ & $52(86.7 \%)$ & \\
\hline
\end{tabular}

Table 2. Median (01-03) of macro and micronutrients intake adjusted by the estimated total daily intake of old adults with and without MetS, Aiquara, Bahia, Brazil (2015)

\section{Variables}

Without MetS

With MetS

p

Effect size (r)

Macronutrients

Estimated daily carbohydrate intake (g)

Estimated daily lipid intake $(\mathrm{g})$

Estimated daily protein intake $(\mathrm{g})$

$\%$ of total caloric intake from carbohydrates

$\%$ of total caloric intake from lipids

$\%$ of total caloric intake from protein

Estimated daily protein intake normalized by body weight $(\mathrm{g} / \mathrm{BW})$

\begin{tabular}{|l|l|}
\hline $112.95(157.01-206.47)$ \\
\hline $39.32(29.33-50.54)$ \\
\hline $79.68(59.34-102.51)$ \\
\hline $0.49(0.47-0.51)$ \\
\hline $0.26(0.25-0.27)$ \\
\hline $0.24(0.23-0.25)$ \\
\hline $1.39(1.05-1.76)$
\end{tabular}

\begin{tabular}{|l|l|}
\hline $166.43(125.48-217.30)$ \\
\hline $28.93(19.65-40.47)$ \\
\hline $60.13(41.23-83.62)$ \\
\hline $0.58(0.56-0.60)$ \\
$0.22(0.21-0.23)$ \\
$0.20(0.19-0.20)$ \\
\hline $0.91(0.59-1.29)$
\end{tabular}

\begin{tabular}{|l|l|}
\hline 0.149 & $0.12^{¥}$ \\
\hline $0.002^{*}$ & $0.25^{\ominus}$ \\
\hline $0.005^{*}$ & 0.22 \\
\hline$<0.001^{*}$ & $0.76^{\S}$ \\
\hline$<0.001^{*}$ & $0.71 \S$ \\
\hline$<0.001^{*}$ & $0.78^{\S}$ \\
\hline$<0.001^{*}$ & $0.33^{\ominus}$ \\
\hline
\end{tabular}

Fatty acids \& micronutrients

Estimated daily monounsaturated fatty acids intake $(\mathrm{g})$

Estimated daily polyunsaturated fatty acids intake $(\mathrm{g})$

Estimated daily copper intake (mg)

Estimated daily manganese intake $(\mathrm{mg})$

Estimated daily niacin intake (mg)

Estimated daily riboflavin intake (mg)

Estimated daily vitamin A intake (mg)

Estimated daily vitamin B6 intake $(\mathrm{mg})$

Estimated daily vitamin C intake (mg)

Estimated daily zinc intake $(\mathrm{mg})$

\begin{tabular}{|l|l|l|l|}
\hline $10.51(8.49-12.79)$ & $8.76(6.87-11.09)$ & $0.016^{*}$ & $0.19^{¥}$ \\
\hline $5.93(4.69-7.32)$ & $4.48(3.33-5.92)$ & $0.001^{*}$ & $0.27^{\ominus}$ \\
\hline $0.85(0.71-1.01)$ & $0.71(0.58-0.87)$ & $0.005^{*}$ & $0.22^{¥}$ \\
\hline $1.22(1.02-1.45)$ & $1.34(1.16-1.58)$ & $0.004^{*}$ & $0.22^{¥}$ \\
\hline $23.64(18.32-29.61)$ & $20.22(15.28-26.36)$ & 0.103 & $0.13^{¥}$ \\
\hline $1.21(1.01-1.44)$ & $1.09(0.90-1.32)$ & 0.151 & $0.11^{¥}$ \\
\hline $527.55(496.99-561.85)$ & $396.58(368.18-431.87)$ & $<0.001^{*}$ & $0.68^{\S}$ \\
\hline $1.70(1.33-2.10)$ & $1.30(0.97-1.72)$ & $0.001^{*}$ & $0.25^{\ominus}$ \\
\hline $54.35(50.85-58.27)$ & $108.12(104.87-112.16)$ & $<0.001^{*}$ & $0.76^{\S}$ \\
\hline $12.14(8.43-16.30)$ & $9.75(6.30-14.03)$ & 0.102 & $0.13^{¥}$ \\
\hline ize $(r)$ was considered as small when $r \leq 0.1,(*)$, medium when $r \geq 0.24(\theta)$, large when $r \geq 0.37(\S)$, MetS: Metabolic syndrome \\
\hline
\end{tabular}

$\left.{ }^{*}\right)$ Significant difference between groups $(p<0.05)$, the effect size $(r)$ was considered as small when $r \leq 0.1,(*)$, medium when $r \geq 0.24(\theta)$, large when $r \geq 0.37(\S)$, MetS: Metabolic syndrome 
serum uric acid among the old adults with MetS, indicating a worrying pro-oxidant state. These results were associated to a dietary profile characterized by a higher percentage of carbohydrates and lower percentage of proteins and lipids among old adults with MetS, when compared to old adults without MetS. Additionally, the daily intake of potentially antioxidant micronutrients, mono and polyunsaturated fatty acids, copper and vitamins A and B6 were higher among old adults without MetS, while manganese and vitamin $\mathrm{C}$ was higher among those with MetS.

The high prevalence of MetS in this population is like previous study developed in Brazil. Salaroli et al. (20) found a prevalence of 48.3\% in adults between 55 and 64 years, demonstrating a trend to higher prevalence of MetS among old adults. The fact that most studies report the prevalence of MetS in the general population, regardless of age, limits the comparison of

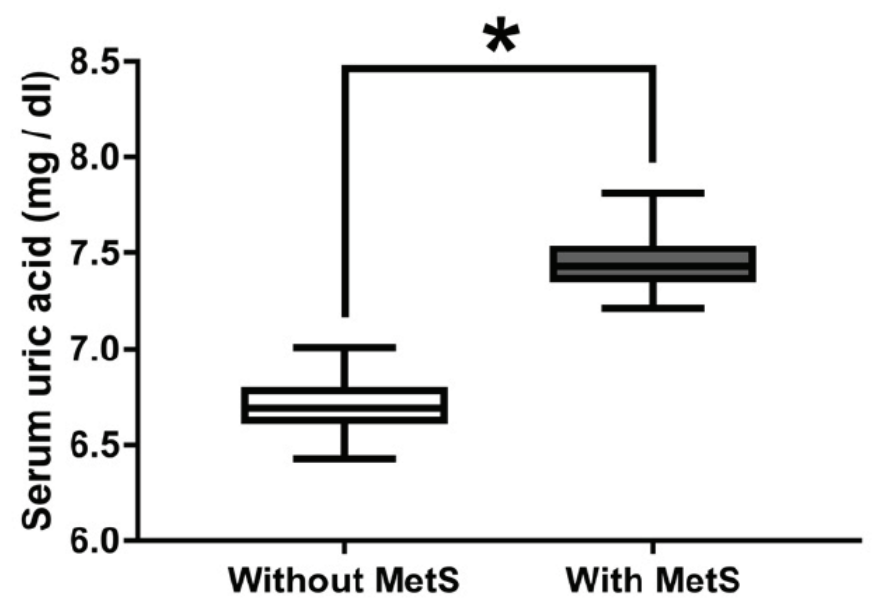

Figure 1. Serum uric acid from the community-dwelling old adults with and without Metabolic syndrome $\left({ }^{*}\right)$ Significant difference between groups $(\mathrm{p}<0.05)$

MetS: Metabolic syndrome

Table 3. Antihypertensive drugs use among studied old adults with and without MetS, Aiquara, Bahia, Brazil (2015)

\begin{tabular}{|l|l|l|l|} 
Variables & Without MetS & With MetS & p
\end{tabular}

\begin{tabular}{|c|c|c|c|c|}
\hline \multirow{2}{*}{$\begin{array}{l}\text { ACE } \\
\text { inhibitors* }\end{array}$} & No & 74 (83.1\%) & $46(85.2 \%)$ & \multirow{2}{*}{0.748} \\
\hline & Yes & $15(16.9 \%)$ & $8(14.8 \%)$ & \\
\hline \multirow{2}{*}{$\beta$ blockers } & No & $80(89.9 \%)$ & $42(79.2 \%)$ & \multirow{2}{*}{0.078} \\
\hline & Yes & $9(10.1 \%)$ & $11(20.8 \%)$ & \\
\hline \multirow{2}{*}{$\alpha-1$ blockers } & No & 89 (100.0\%) & $53(100.0 \%)$ & \multirow{2}{*}{-} \\
\hline & Yes & $0(0.0 \%)$ & $0(0.0 \%)$ & \\
\hline \multirow{2}{*}{ Ca blockers ${ }^{* *}$} & No & $74(85.1 \%)$ & $43(81.1 \%)$ & \multirow{2}{*}{0.543} \\
\hline & Yes & $13(14.9 \%)$ & $10(18.9 \%)$ & \\
\hline \multirow{2}{*}{$\mathrm{ARB}^{* * *}$} & No & $67(75.3 \%)$ & $40(75.5 \%)$ & \multirow{2}{*}{0.980} \\
\hline & Yes & $22(24.7 \%)$ & $13(24.5 \%)$ & \\
\hline
\end{tabular}

${ }^{*}$ Angiotensin-converting enzyme (ACE) inhibitors, ${ }^{* *}$ Calcium channel blockers, ${ }^{* * *}$ Angiotensin-II receptor blockers (ARB), MetS: Metabolic syndrome our results with other studies, although the high prevalence of MetS in the studied population is expected, owing to the agingassociated metabolic changes. Considering a global scenario, previous studies report very different prevalences, which can be justified by the different diagnostic criteria used, as well as the different populations involved. Ford et al. (21), found a prevalence of $43.5 \%$ of MetS among American old adults, while Miccoli et al. (22) found a prevalence of 25\% in Italian individuals over 70 years old. Cankurtaran et al. (23) identified a MetS prevalence of $23.8 \%$ in Turkish old adults, whereas in a study conducted among Ecuadorians older adults, it was found a prevalence of $66 \%$ of MetS among women and $47 \%$ among men (24).

In our study, the sex was not an associated factor with MetS. However, MetS is admittedly a clinical condition associated with several intervening factors, and in addition to sex, other factors, such as the nutritional profile (25), may contribute to the development of this clinical condition. Indeed, the nutritional profile presented by the studied old adults with and without MetS was significantly different, old adults with MetS presented a nutritional profile with a distribution of caloric intake composed by a higher percentage of carbohydrates and lower of proteins and lipids, when compared to those without MetS. It is proposed that a daily intake greater than $1.2 \mathrm{~g} / \mathrm{kg}$ to $1.5 \mathrm{~g} /$ $\mathrm{kg}$ of protein and less than 130 to 150 grams of carbohydrates per day is associated with weight loss, but with maintenance of muscle mass, improved glycemic control, and reduction of plasma triglyceride levels, as well as an effective treatment of MetS $(26,27)$.

Although this population presented a daily protein intake higher than that recommended by the World Health Organization (WHO) (28), which is $0.8 \mathrm{~g} / \mathrm{kg}$, individuals without MetS had an even higher estimated daily intake of protein when compared to the MetS group. This fact indicates that the WHO recommendation may possibly be underestimated for the daily required intake for old adults, making old adults with low protein consumption prone to develop MetS. Then, it is suggested that the future recommendations should consider an increased value of daily protein intake to prevent MetS, following the recommendation proposed to the maintenance of lean mass and prevention of sarcopenia, which suggests a daily protein intake of $1.2 \mathrm{~g} / \mathrm{kg}$ (29). The loss of lean mass, a natural consequence of the aging process, accelerated by a low daily protein intake may help to explain the greater susceptibility to metabolic disorders typical of MetS, since the muscle is a metabolically more active tissue than adipose tissue (26).

The highest lipid intake observed among the old adults without MetS seems to be in contradistinction to the concepts related to the nutritional recommendations to the clinical condition studied here, since it is a risk factor for the development of 
dyslipidemias and cardiovascular diseases (27). However, two factors need to be noted: 1) despite being significantlly greater among old adults without MetS, lipid intake was within the recommended range (20\%-35\% of caloric intake) (27) and, 2) proportionally, a high consumption of unsaturated fatty acids in relation to the saturated fatty acids is indicated as a metabolic protective strategy $(30,31)$. In our study, the old adults without MetS, despite presenting higher consumption of lipids, also presented higher intakes of unsaturated fatty acids. In this context, a diet with a higher amount of unsaturated fatty acids (32), as well as with a higher amount of micronutrients with antioxidant potential, is efficient for weight loss and blood pressure reduction, important strategies for coping with MetS $(27,33)$.

Many micronutrients have been widely pointed as potential antioxidant agents and therefore, metabolic and cardiovascular risk protectors (2). Several studies suggest that the increase of micronutrients consumption, such those studied here (ie, copper, manganese, niacin, riboflavin, vitamins $A, B 6, C$ and zinc) and the consequent increase in their plasma levels may be strategies potentially beneficial for the reduction of MetS risk factors $(34,35)$.

Serum low levels of vitamin B6 were associated with a proinflammatory status and high oxidative stress rates in Puerto Rican adults (36). In fact, vitamin B6 is reported in the literature as an important antioxidant agent, being able to minimize the inflammatory status, as observed in obese individuals (37). Additionally, Gregory et al. (38) showed metabolic changes after inducing B6 hypovitaminosis in healthy subjects. Our results, together with above cited studies, may help to support the association between low vitamin B6 intake, MetS and high serum concentration of uric acid, a biomarker of prooxidant state, present among old adults with MetS. In the same perspective, a low vitamin A intake is also reported as associated to MetS and non-alcoholic fatty liver disease (39), also due to its antioxidant potential, which corroborate with our results, since we observed that old adults with MetS presented a lower daily intake of this vitamin.

The relationship between the daily intake of copper and the health status is really complex, once its intake above the recommended upper limit may induced a pro-inflammatory and pro-oxidant status, on the other hand, copper deficiency, owing to a low daily consumption of this micronutrient, is associated with an unfavorable metabolic pattern (38). Our results showed a higher consumption of copper among the old adults without MetS, but within recommended ranges in the literature (up to $3 \mathrm{mg} /$ day) (39), which does not put these old adults in a health risk condition.

The vitamin C, widely recognized for its antioxidant properties and whose intake was associated with a reduction in the risk of MetS in Korean adults (40), presented a controversial result in our study, since the old adults with MetS exhibited a higher intakes of this vitamin, when compared to old adults without MetS. Likewise, the old adults with MetS presented greater daily consumption of manganese, a micronutrient also recognized for its antioxidant properties and association with a lower risk to develop MetS (41). These results of daily consumption of vitamin $C$ and manganese indicate that the greater consumption of these important micronutrients with protective role against MetS had no positive impact on the disease and, in addition, did not contribute to the control of the pro-oxidant status in these individuals, since they had a higher serum uric acid concentration. It is plausible to hypothesize that the inadequate nutritional profile of macronutrients observed here could minimize the protective effect of a higher vitamin C and manganese intake among old adults with MetS.

The use of a 24-hour recall for estimate the daily nutritional profile could be pointed as a limitation of this study, but it was considered an adequate tool for the use with elderly population (14).

\section{Study Limitations}

Additionally, the lack of standard diagnostic criteria for MetS, specifically for elderly population, could also be listed as limitations. Although the limitations, our results indicate that a nutritional profile with a high proportion of carbohydrates and low proportion of lipids and proteins, together with a lower daily intake of the micronutrients copper, vitamin A and B6 is associated to MetS in the community-dwelling old adults. Such nutritional profile may affect the possible benefits of a higher daily intake of important antioxidant micronutrients, such as vitamin $\mathrm{C}$ and manganese, and this fact may be related to the inability to correct the pro-oxidant status observed among old adults with MetS, evidenciated by the higher serum levels of uric acid. It is important to note that there was not observed significant association between antihypertensive drugs use and MetS diagnosis. Antiantihypertensive drugs, especially diuretics, beta-blockers and alpha-1 blockers (19), could influence the serum uric acid.

\section{Conclusion}

This find reinforce the hypothesis that the association between serum uric acid and MetS occur owing to metabolic imbalance present in the patients with MetS.

Further studies should expand our analysis with greater sample, the main limitation from our study, aiming to confirm or refute our findings. Additionally, further studies should focus on refining/standardize the diagnostic criteria for MetS specifically for the elderly population, as well as expanding the analysis proposed here, evaluating the consumption of 
more micronutrients and the serum concentration of other biomarkers of pro-oxidant and pro-inflammatory status.

\section{Acknowledgments}

The authors would like to thank all of the research assistants involved in this project for their assistance with participant recruitment.

\section{Ethics}

Ethics Committee Approval: All procedures were conducted in conformity with the Helsinki Declaration and the study was submitted and approved by the local Human Research Ethics Committee (protocol\#:729.303).

Informed Consent: Written informed consent was obtained from the volunteers.

Peer-review: Externally peer-reviewed.

\section{Authorship Contributions}

Concept: R.D.S.C., R.P., Design: C.A.C., R.P., Data Collection or Processing: I.V.F., D.P.D.S., Í.JS.R., Analysis or Interpretation: C.S.D.S., R.D.S.C., C.A.C., R.P., Literature Search: I.V.F., D.P.D.S., Í.JS.R., C.S.D.S., Writing: I.V.F., D.P.D.S., İ.JS.R., C.S.D.S., R.D.S.C., C.A.C., R.P.

Conflict of Interest: The author(s) declared no potential conflicts of interest with respect to the research, authorship, and/or publication of this article.

Financial Disclosure: This project received financial support from Fundação de Amparo à Pesquisa do Estado da Bahia (award numbers SUS 0055/2013).

\section{References}

1. Grundy SM, Cleeman JI, Daniels SR, Donato KA, Eckel RH, Franklin BA, Gordon DJ, Krauss RM, Savage PJ, Smith SC Jr, Spertus JA, Costa F; American Heart Association; National Heart, Lung, and Blood Institute. Diagnosis and management of the metabolic syndrome: an American Heart Association/ National Heart, Lung, and Blood Institute Scientific Statement. Circulation 2005;112:2735-2752.

2. Wei J, Zeng C, Gong QY, Li XX, Lei GH, Yang TB. Associations between Dietary Antioxidant Intake and Metabolic Syndrome. PLoS One 2015;10:0130876.

3. Rigo JC, Vieira JL, Dalacorte RR, Reichert CL. Prevalence of metabolic syndrome in an elderly community: comparison between three diagnostic methods. Arq Bras Cardiol 2009;93:85-91.

4. Yang YL, Mo YP, He YS, Yang F, Xu Y, Li CC, Wang J, Reng HM, Long L. Correlation between renin-angiotensin system gene polymorphisms and essential hypertension in the Chinese Yi ethnic group. J Renin Angiotensin Aldosterone Syst 2015;16:975-981.

5. Rani V, Deep G, Singh RK, Palle K, Yadav UC. Oxidative stress and metabolic disorders: Pathogenesis and therapeutic strategies. Life Sci 2016;148:183193.

6. Chang JB, Chen $\mathrm{YL}$, Hung $\mathrm{YJ}$, Hsieh $\mathrm{CH}$, Lee $\mathrm{CH}$, Pei $\mathrm{D}$, Lin JD, $\mathrm{Wu} \mathrm{CZ}$, Liang YJ, Lin CM. The Role of Uric Acid for Predicting Future Metabolic Syndrome and Type 2 Diabetes in Older People. J Nutr Health Aging 2017;21:329-335.
7. Fang J, Alderman MH. Serum uric acid and cardiovascular mortality the NHANES I epidemiologic follow-up study, 1971-1992. National Health and Nutrition Examination Survey. JAMA 2000;283:2404-2410.

8. Niskanen LK, Laaksonen DE, Nyyssönen K, Alfthan G, Lakka HM, Lakka TA Salonen JT. Uric acid level as a risk factor for cardiovascular and all-cause mortality in middle-aged men: a prospective cohort study. Arch Intern Med 2004;164:1546-1551.

9. Yadav D, Lee ES, Kim HM, Choi E, Lee EY, Lim JS, Ahn SV, Koh SB, Chung $\mathrm{CH}$. Prospective study of serum uric acid levels and incident metabolic syndrome in a Korean rural cohort. Atherosclerosis 2015;241:271-277.

10. Choi H, Kim HC, Song BM, Park JH, Lee JM, Yoon DL, Yoon YM, Rhee $Y$, Youm Y, Kim CO. Serum uric acid concentration and metabolic syndrome among elderly Koreans: The Korean Urban Rural Elderly (KURE) study. Arch Gerontol Geriatr 2016;64:51-58.

11. Liu Z, Que S, Zhou L, Zheng S. Dose-response Relationship of Serum Uric Acid with Metabolic Syndrome and Non-alcoholic Fatty Liver Disease Incidence: A Meta-analysis of Prospective Studies. Sci Rep 2015;5:14325.

12. Marotta $T$, Liccardo $M$, Schettini $F$, Verde $F$, Ferrara AL. Association of hyperuricemia with conventional cardiovascular risk factors in elderly patients. J Clin Hypertens (Greenwich) 2015;17:27-32.

13. WHO. Global recommendations on physical activity for health. Geneva: World Health Organization. 2010;1-60.

14. Rutishauser IH. Dietary intake measurements. Public Health Nutr 2005;8:1100-1107.

15. da Silva JRD, Freire IV, Ribeiro IJS, Dos Santos CS, Casotti CA, Dos Santos DB, Barbosa AAL, Pereira R. Improving the comprehension of sarcopenic state determinants: An multivariate approach involving hormonal, nutritional, lifestyle and genetic variables. Mech Ageing Dev 2018;173:21-28.

16. Willett WC, Howe GR, Kushi LH. Adjustment for total energy intake in epidemiologic studies. Am J Clin Nutr 1997;65:1220-1228.

17. Pallant J. A Step by Step Guide to Data Analysis Using the SPSS Program. 4th ed. Berkshire: McGraw-Hill Education 2010;1-295.

18. Fritz CO, Morris PE, Richler JJ. Effect size estimates: current use, calculations, and interpretation. J Exp Psychol Gen 2012;141:2-18.

19. Ueno S, Hamada T, Taniguchi S, Ohtani N, Miyazaki S, Mizuta E, Ohtahara A, Ogino K, Yoshida A, Kuwabara M, Yoshida K, Ninomiya H, Kotake H, Taufiq F, Yamamoto K, Hisatome I. Effect of Antihypertensive Drugs on Uric Acid Metabolism in Patients with Hypertension: Cross-Sectional Cohort Study. Drug Res (Stuttg) 2016;66:628-632.

20. Salaroli LB, Barbosa GC, Mill JG, Molina MC. Prevalência de síndrome metabólica em estudo de base populacional, Vitória, ES-Brasil [Prevalence of metabolic syndrome in population-based study, Vitória, ES-Brazil]. Arq Bras Endocrinol Metabol 2007;51:1143-1152.

21. Ford ES, Giles WH, Dietz WH. Prevalence of the metabolic syndrome among US adults: findings from the third National Health and Nutrition Examination Survey. JAMA 2002;287:356-359.

22. Miccoli R, Bianchi C, Odoguardi L, Penno G, Caricato F, Giovannitti MG, Pucci $\mathrm{L}$, Del Prato S. Prevalence of the metabolic syndrome among Italian adults according to ATP III definition. Nutr Metab Cardiovasc Dis 2005;15:250254

23. Cankurtaran M, Halil M, Yavuz BB, Dagli N, Oyan B, Ariogul S. Prevalence and correlates of metabolic syndrome (MS) in older adults. Arch Gerontol Geriatr 2006;42:35-45.

24. Orces $\mathrm{CH}$, Gavilanez EL. The prevalence of metabolic syndrome among older adults in Ecuador: Results of the SABE survey. Diabetes Metab Syndr 2017;11:555-560.

25. Bernabé García J, Zafrilla Rentero P, Mulero Cánovas J, Gómez Jara P, Leal Hernández $\mathrm{M}$, Abellán Alemán J. Biochemical and nutritional markers and antioxidant activity in metabolic syndrome. Endocrinol Nutr 2014;61:302308. 
26. Bauer J, Biolo G, Cederholm T, Cesari M, Cruz-Jentoft AJ, Morley JE, Phillips S, Sieber C, Stehle P, Teta D, Visvanathan R, Volpi E, Boirie Y. Evidencebased recommendations for optimal dietary protein intake in older people: a position paper from the PROT-AGE Study Group. J Am Med Dir Assoc 2013;14:542-559.

27. Botchlett R, Woo SL, Liu M, Pei Y, Guo X, Li H, Wu C. Nutritional approaches for managing obesity-associated metabolic diseases. J Endocrinol 2017;233:145-171.

28. WHO Food and nutrition technical report series: Protein and amino acids requirements. Rome: Joint FAO/WHO/UNU Expert Consultation 2007; P 265.

29. Morley JE, Argiles JM, Evans WJ, Bhasin S, Cella D, Deutz NE, Doehner W, Fearon KC, Ferrucci L, Hellerstein MK, Kalantar-Zadeh $K$, Lochs $H$ MacDonald N, Mulligan K, Muscaritoli M, Ponikowski P, Posthauer ME, Rossi Fanelli F, Schambelan M, Schols AM, Schuster MW, Anker SD; Society for Sarcopenia, Cachexia, and Wasting Disease. Nutritional recommendations for the management of sarcopenia. J Am Med Dir Assoc 2010;11:391-396.

30. Yary $T$, Voutilainen $S$, Tuomainen TP, Ruusunen A, Nurmi T, Virtanen JK. Omega-6 polyunsaturated fatty acids, serum zinc, delta-5- and delta-6desaturase activities and incident metabolic syndrome. J Hum Nutr Diet 2017;30:506-514

31. Zehr KR, Walker MK. Omega-3 polyunsaturated fatty acids improve endothelial function in humans at risk for atherosclerosis: A review. Prostaglandins Other Lipid Mediat 2018;134:131-140.

32. Mozaffarian D, Micha $R$, Wallace $S$. Effects on coronary heart disease of increasing polyunsaturated fat in place of saturated fat: a systematic review and meta-analysis of randomized controlled trials. PLoS Med 2010;7:1000252.

33. Sacks FM, Svetkey LP, Vollmer WM, Appel U, Bray GA, Harsha D, Obarzanek E, Conlin PR, Miller ER, Simons-Morton DG, Karanja N, Lin PH; DASH-Sodium Collaborative Research Group. Effects on blood pressure of reduced dietary sodium and the Dietary Approaches to Stop Hypertension (DASH) diet. DASH-Sodium Collaborative Research Group. N Engl J Med 2001;344:3-10.
34. Lee Jl, Lee Y, Kim YL, Cho HW. Effect of implant number and distribution on load transfer in implant-supported partial fixed dental prostheses for the anterior maxilla: A photoelastic stress analysis study. J Prosthet Dent 2016;115:161-169.

35. Akter S, Eguchi M, Kurotani K, Kochi T, Kashino I, Ito R, Kuwahara K, Tsuruoka H, Kabe I, Mizoue T. Serum 25-hydroxyvitamin D and metabolic syndrome in a Japanese working population: The Furukawa Nutrition and Health Study. Nutrition 2017;36:26-32.

36. Shen J, Lai CQ, Mattei J, Ordovas JM, Tucker KL. Association of vitamin B-6 status with inflammation, oxidative stress, and chronic inflammatory conditions: the Boston Puerto Rican Health Study. Am J Clin Nutr 2010;91:337-342.

37. Lotto V, Choi SW, Friso S. Vitamin B6: a challenging link between nutrition and inflammation in CVD. Br J Nutr 2011;106:183-195.

38. Gregory JF, Park Y, Lamers $Y$, Bandyopadhyay N, Chi YY, Lee K, Kim S, da Silva V, Hove N, Ranka S, Kahveci T, Muller KE, Stevens RD, Newgard CB, Stacpoole PW, Jones DP. Metabolomic analysis reveals extended metabolic consequences of marginal vitamin B-6 deficiency in healthy human subjects. PLoS One 2013;8:63544.

39. Musso G, Gambino R, De Michieli F, Biroli G, Premoli A, Pagano G, Bo S, Durazzo $M$, Cassader M. Nitrosative stress predicts the presence and severity of nonalcoholic fatty liver at different stages of the development of insulin resistance and metabolic syndrome: possible role of vitamin A intake. Am J Clin Nutr 2007;86:661-671.

40. Kim J, Choi YH. Physical activity, dietary vitamin $C_{\text {, and metabolic syndrome }}$ in the Korean adults: the Korea National Health and Nutrition Examination Survey 2008 to 2012. Public Health 2016;135:30-37.

41. Li Y, Guo H, Wu M, Liu M. Serum and dietary antioxidant status is associated with lower prevalence of the metabolic syndrome in a study in Shanghai, China. Asia Pac J Clin Nutr 2013;22:60-68. 